RESEARCH

\title{
THE EFFECT OF FRAILTY LEVEL ON ACCEPTANCE OF ILLNESS IN OLDER PEOPLE WITH CHRONIC OBSTRUCTIVE PULMONARY DISEASE
}

Turkish Journal of Geriatrics

DOI: 10.31086/tigeri.2021.221

$2021 ; 24(2): 244-254$

- Canan BOZKURT ${ }^{1}$

- Yasemin YILDIRIM²

- Fisun ŞENUZUN AYKAR ${ }^{3}$

\section{Abstract}

Introduction: The aim of this study is to examine the effect of frailty level on acceptance of illness in older people with Chronic Obstructive Pulmonary Disease. A descriptive and correlational design was used.

Materials and Methods: The sample comprised 311 Chronic Obstructive Pulmonary Disease patients aged 65 years and older who applied to the Chest Diseases outpatient clinics of the Chest Diseases and Surgery Hospital between February-April 2018. The Individual Diagnostic Form, the Edmonton Frailty Scale, and the Acceptance of Illness Scale were used. The Statistical Package for Social Science 23.0 was used for analysing the data.

Results: The mean age of the patients included in the study was 71.7 \pm 6.0 , and $74 \%$ of the patients were male. The mean score of frailty of the patients was found to be $5.00 \pm 3.36$, and $49.8 \%$ were not frail. The mean score of acceptance of illness was $26.99 \pm 8.44$. According to the results of the study, there was a strong negative correlation between the level of frailty and the level of acceptance of illness in older people $(p<0.05 ; r=-0.747)$; the explanatory power of the relationship between the level of frailty and acceptance of illness is $55.6 \%\left(R^{2}=0.556, p<0.001\right)$.

Conclusion: It is thought that the increase in the acceptance of illness level of the older people significantly associated with the decrease in frailty.

Keywords: Frailty; Geriatrics; Pulmonary Disease, Chronic Obstructive

Received: Mar 26, 2021

Accepted: May 16, 2021

${ }^{1}$ Bandirma Onyedi Eylul University, Faculty of Health Sciences, Department of Nursing, Balkesir, Turkey

2 Ege University, Nursing Faculty, Department of Internal Medicine Nursing, Izmir, Turkey

${ }^{3}$ Izmir Tinaztepe University, Faculty of Health Sciences, Department of Nursing, Izmir, Turkey 


\section{INTRODUCTION}

Chronic Obstructive Pulmonary Disease (COPD) holds an important place among public health problems in the world and due to the heavy burden of the disease (1). According to data from the World Health Organization (WHO), 5.6\% of all deaths in 2015 were due to COPD, which makes it the fourth most common cause of death. The Burden of Obstructive Lung Disease (BOLD) study and other epidemiological studies have reported that the number of COPD cases in 2010 was 384 million, which covered $11.7 \%$ of the global population (2). Likewise, the prevalence study conducted in Turkey in 2011 is $5.3 \%$, COPD ranks as the third most common cause of death, and it is estimated that every year about 30 thousand people die a result of COPD $(2,3)$. Apart from chronic diseases such as COPD, which are more common with increasing age, degenerations caused by aging lead to a decrease in the ability of the organs to adapt, which -in some cases - causes geriatric syndromes. Along with immobilization, incontinence, depression, delirium, falls, and osteoporosis - all common examples of geriatric syndromes and diseases - Frailty Syndrome is also commonly seen in older people $(3,4)$.

Frailty Syndrome describes several negative health outcomes such as decrease in physiological reserve, stress intolerance, low physical activity, weakness, slowness, sarcopenia, and unwanted weight loss. While this syndrome is seen in $7 \%$ of people aged over 65, it is estimated to be present in $30-45 \%$ of people over 80 years of age; however, it is not possible to come to an exact prevalence rate, since many factors such as psychological-cognitive, physical, economic and social status of people have an impact on their frailty levels $(5,6)$. Diagnosis of this syndrome at later ages is very difficult because it is associated with many chronic diseases that increase the patient's disability, hospitalization rates, health care costs, and mortality. On the other hand, a cause-effect relationship cannot be established due to the presence of other geriatric syndromes along with Frailty Syndrome $(4,7)$.

As with many other diseases, the patient lives in uncertainty until the diagnosis is made in COPD. This sometimes causes emotional trauma in patients and often leads to acute stress reactions such as fear of loss of control, concentration problems, hopelessness, and the feeling that the situation is unreal. Therefore, the most important way to learn to cope with the disease is to help the patient accept the disease (8). In this way, the individual will be capable of restricting his or her negative feelings and increasing beneficial behaviours that improve and protect his or her health $(9,10)$. People who can accept their disease can make better choices about their daily activities, and cope better with the problems caused by the disease $(9,11)$. Failure to accept the disease, however, leads to an increase in the sense of dependence and a decrease in self-efficacy and self-esteem (8).

Considering all aspects of COPD and frailty syndrome, the level of accepting the disease complicates the adaptation process of older people (6). Acceptance of the disease plays an important role in the adaptation to the disease as well as treatment, and it is associated with recognizing the limitations it causes. Two of the determinants of the acceptance of the disease are chronic diseases such as COPD and geriatric syndromes such as frailty. Acceptance of illness is an important factor that can contribute to improvement in the prognosis and treatment of Frailty Syndrome (12). Although there are not enough data in the literature, a few studies have shown that higher levels of frailty lead to lower acceptance of the disease (13). To the best of our knowledge, there has been no study in Turkey evaluating the effect of the level of frailty on the acceptance of the disease in older people with COPD. Therefore, the purpose of this study was to investigate the effect of frailty level on the acceptance of the disease in older people with COPD. 


\section{MATERIALS and METHODS}

After obtaining permission from the Medical Faculty Ethics Committee (17-12.1 / 30) of a university, the approval of the Provincial Health Directorate was also obtained. The authors of the Turkish versions of the scales were contacted by e-mail and their approval was obtained.

\section{Sample}

G-Power statistical analysis was performed to determine the sample size. When the sample size is calculated, the minimum number of samples that should be reached for Cohen's effect size $\rho=0.2$ with alpha $=0.05,0.80$ power is determined as 197 patients.

The data of the study were collected from İzmir Dr. Suat Seren Chest Diseases and Surgery Hospital Chest Diseases Polyclinics between February and April 2018. The aim of the study was explained by the researcher to the patients included in the study and data were collected after they signed written and oral informed consent. To collect data, 10-15 minute one-to-one interviews were conducted with 311 COPD patients 65 years and older. Questionnaire questions were asked to the patient and the answers were recorded by the researcher. Inclusion criteria were set as follows: being diagnosed with COPD at least one year prior to the study; being 65 years and over; being literate; having access to the results of the Respiratory Function Test; voluntary participation in the study; and signing the informed consent form. Exclusion criteria were as follows: coexistence of other chronic lung diseases such as asthma, active tuberculosis, lung cancer, bronchiectasis, sarcoidosis, pulmonary fibrosis, primary pulmonary hypertension, interstitial lung disease or any other active lung disease; presence of hemodynamic instability caused by chronic diseases other than COPD; presence of severe exacerbations of diseases other than COPD; and presence of a se- rious psychiatric disorder requiring treatment (13).

\section{Materials Used}

\section{Individual Diagnostic Form}

Based on the information collected from the literature, this form was composed by the researchers and consisted of four sections including socio-demographic characteristics, health and disease characteristics, mMRC dyspnea scale and forced expiratory volume in 1 st second $\left(\mathrm{FEV}_{1}\right)$ value measured in the last 3 months.

\section{NRS-2002 Nutritional Risk Screening}

This tool aims to identify malnutrition and malnutrition risk, as well as to identify patients who may be in need of nutritional support. A score between $0-3$ is allocated for each section, and one point is added to the total score for patients above 70 years of age. Patients with a total score of $\geq 3$ are considered to be at nutritional risk (14).

\section{Edmonton Frailty Scale (EFS)}

In the validity and reliability study of the scale conducted by Eskiizmirli Aygör et al. In 2013, the scale consists of 11 items and the total score is used for evaluation. The lowest and highest total scores from the scale are 0 and 17, respectively. Higher total scores represent an increase in severity of vulnerability (15).

\section{Acceptance of Illness Scale (AIS)}

The validity and reliability of the Turkish version was confirmed by Besen in 2009, and the total score range of the scale consisting of eight main headings is between 8-40. This Likert-type scale is rated by 5 points on participation/non-participation of the individual. Higher scores indicate higher levels of acceptance of the illness, which in return, indicate the patient's less negative reactions to the adverse outcomes of the illness (8). 


\section{Assessment of Data}

The analysis of the study data was carried out using the SPSS (Statistical Package for Social Sciences v.23, IBM Corp., Armonk, NY, USA) statistical analysis software.

Mean values and standard deviations were calculated for the variables. Independent Sample $t$ test, Paired Sample t test, Mann Whitney U, One Way ANOVA, and Kruskall Wallis $\mathrm{H}$ were used to evaluate differences between variables (depending on whether or not they were normally distributed); Pearson Correlation Analysis was used to evaluate relationship (because dependent variables are normally distributed); and Tukey's HSD Test for normally distributed variables and Bonferroni (Dunn) Test for abnormally distributed variables were used for further analysis. Multivariate linear regression analysis was used to evaluate the existing significant relationship; Adjust $\mathrm{R}^{2}$ was used to compare the explanatory power of each linear regression model.

\section{RESULTS}

The mean age of the patients included in the study was $71.7 \pm 6.0$ and the mean duration of COPD was 6.27 years \pm 4.55 . The mean score of $m M R C$ was $1.71 \pm 1$ and $44.4 \%$ had an mMRC score of "one". While the mean $\mathrm{FEV}_{1}$ value of the patients was $51.61 \pm 17.46,43.4 \%$ of these patients were GOLD II. The mean NRS-2002 score of the sample was $2.00 \pm 0.83$ and $65.6 \%$ were not at risk $(<3)$. The mean score of the Acceptance of Illness Scale was $26.99 \pm 8.44$. The Edmonton Frailty Scale mean score was $5.00 \pm 3.36$ and $49.8 \%$ of the patients were not frail (Table 1).

Among all patients, $74 \%$ were male, $64.3 \%$ were married, and $66.2 \%$ were primary or secondary school graduates. $65.2 \%$ of the patients were retired and $68.2 \%$ reported that their incomes were equal to their expenses. According to the analysis, while the women's frailty score was higher than the men's $(p<0.05)$; there was no difference between the ac- ceptance of illness scores between the genders ( $p>0.05)$. Considering other socio-demographic characteristics, it was found that being single/widowed, having a low level of education, being unemployed, and having a low level of income were associated with higher levels of frailty and lower scores of acceptance of illness $(p<0.05)$ (Table 2).

Of the 311 patients in this study, 55\% stated that they had quit smoking, $72.7 \%$ indicated that they did not drink alcohol at all. In terms of smoking, there was no difference in the frailty and acceptance of illness scores of the patients ( $p>0.05)$. In terms of alcohol usage, while there was no difference in acceptance of illness scores ( $p>0.05)$, patients who used/quit alcohol had lower scores of frailty $(p<0.05)$. It was reported that $53.7 \%$ of the patients had COPD for less than five years, $60.1 \%$ had not been hospitalized due to COPD exacerbation in the last year, and $74.9 \%$ did not use an oxygen device at home. It was indicated that $47.6 \%$ of the patients had comorbidities along with COPD, and $11.5 \%$ of the sample group used five or more medications daily. Patients who were hospitalized due to COPD exacerbation in the previous year and those who used oxygen devices at home had higher frailty and lower acceptance of illness scores $(p<0.001)$. Similarly, patients with comorbidities along with COPD and those taking five or more drugs daily had higher frailty scores $(p<0.001)$ and lower acceptance of illness scores $(p<0.05)$ (Table 2$)$.

The relationships between some variables of the patients and their frailty and acceptance of illness scores were provided in Table 3 . While there was a moderate positive relationship between the frailty score and the patients' age $(r=0.573)$, there was a negative relationship between age and acceptance of illness score $(r=-0.447)(p<0.001)$. In terms of disease-related parameters, frailty scores had a positive relationship with COPD years $(r=0.344)$; a negative relationship with $\mathrm{FEV}_{1}$ values $(r=-0.344)$; and a positive relationship with mMRC scores $(r=0.569)(p<0.001)$. However, acceptance of illness 
Table 1. Disease characteristics of the study sample $(n=311)$

\begin{tabular}{|c|c|c|}
\hline \multirow{2}{*}{ Characteristics } & $\mathbf{n}$ & $\%$ \\
\hline & Mean \pm SD & Min-Max \\
\hline Age & $71.7 \pm 6.0$ & $65-89$ \\
\hline Mean of COPD Years & $6.27 \pm 4.55$ & $1-20$ \\
\hline mMRC & $1.71 \pm 1.00$ & $0-4$ \\
\hline $\begin{array}{c}\text { mMRC Classification } \\
0 \\
1 \\
2 \\
3 \\
4\end{array}$ & $\begin{array}{c}22 \\
138 \\
71 \\
69 \\
11\end{array}$ & $\begin{array}{c}7.1 \\
44.4 \\
22.8 \\
22.2 \\
3.5\end{array}$ \\
\hline $\mathrm{FEV}_{1}$ & $51.61 \pm 17.46$ & $26-94$ \\
\hline $\begin{array}{l}\text { GOLD Classification } \\
\text { GOLD I } \\
\text { GOLD II } \\
\text { GOLD III } \\
\text { GOLD IV }\end{array}$ & $\begin{array}{c}22 \\
135 \\
131 \\
23\end{array}$ & $\begin{array}{c}7.1 \\
43.4 \\
42.1 \\
7.4\end{array}$ \\
\hline NRS-2002 & $2.00 \pm 0.83$ & $1-5$ \\
\hline $\begin{array}{l}\text { NRS-2002 Classification } \\
\text { No risk (Score <3) } \\
\text { At risk (Score } \geq 3 \text { ) }\end{array}$ & $\begin{array}{l}204 \\
107\end{array}$ & $\begin{array}{l}65.6 \\
34.4\end{array}$ \\
\hline Acceptance of Illness Scale & $26.99 \pm 8.44$ & $8-40$ \\
\hline Edmonton Frailty Scale & $5.00 \pm 3.36$ & $0-17$ \\
\hline $\begin{array}{l}\text { Frailty Classification } \\
\text { Not frailty (0-4) } \\
\text { Apparently vulnerable (5-6) } \\
\text { Slightly frailty (7-8) } \\
\text { Medium frailty (9-10) } \\
\text { Severe frailty }(11-17)\end{array}$ & $\begin{array}{l}155 \\
48 \\
49 \\
43 \\
16\end{array}$ & $\begin{array}{c}49.8 \\
15.5 \\
15.8 \\
13.8 \\
5.1\end{array}$ \\
\hline
\end{tabular}

scores had a negative relationship with COPD years $(r=-0.383)$; a positive relationship with $\mathrm{FEV}_{1}$ values $(r=0.467) ;$ and a negative relationship with $\mathrm{mMRC}$ scores $(r=-0.461)(p<0.001)$. NRS-2002 scores indicating malnutrition risk status had a moderate positive correlation with frailty $(r=0.536)$, and a weak negative correlation with acceptance of illness ( $r=$ $-0.466)(p<0.001)$. A moderate level of positive correlation was found between the patients' frailty level and their ages $(r=0.573), m M R C$ scores $(r=0.569)$, and NRS-2002 scores ( $r=0.536)$; between the frailty levels and the year of COPD, a low level of positive correlation was found between the year of COPD $(r$ $=0.344)(p<0.001)$. However, a low level of nega- 
Table 2. Comparison of frailty and acceptance of illness scores based on demographic and other variables ( $\mathrm{n}=311$ )

\begin{tabular}{|c|c|c|c|c|c|c|}
\hline \multirow{3}{*}{$\begin{array}{l}\text { Characteristics } \\
\text { Gender } \\
\text { Female } \\
\text { Male }\end{array}$} & \multirow{3}{*}{$\begin{array}{c}n \\
\\
\\
81 \\
230 \\
\end{array}$} & \multirow{3}{*}{$\begin{array}{c}\% \\
\\
26.0 \\
74.0 \\
\end{array}$} & \multirow{2}{*}{\multicolumn{2}{|c|}{$\begin{array}{c}\begin{array}{c}\text { Edmonton Frailty } \\
\text { Scale }\end{array} \\
\begin{array}{c}\text { Mean } \pm \mathrm{SD}=5.00 \pm 3.36 \\
\text { (Min-Max: } 0-17)\end{array}\end{array}$}} & \multirow{2}{*}{\multicolumn{2}{|c|}{$\begin{array}{c}\text { Acceptance of Illness Scale } \\
\text { Mean } \pm \text { SD }=26.99 \pm 8.44 \\
(\text { Min-Max: } 8-40)\end{array}$}} \\
\hline & & & & & & \\
\hline & & & $\begin{array}{l}6.00 \pm 3.25 \\
4.65 \pm 3.33\end{array}$ & $\begin{array}{c}t=3.162 \\
p=0.002^{\star \star}\end{array}$ & $\begin{array}{l}25.72 \pm 8.36 \\
27.44 \pm 8.44\end{array}$ & $\begin{array}{l}t=1.595 \\
p=0.113\end{array}$ \\
\hline $\begin{array}{l}\text { Marital Status } \\
\text { Married } \\
\text { Single/Widowed }\end{array}$ & $\begin{array}{l}200 \\
111 \\
\end{array}$ & $\begin{array}{l}64.3 \\
35.7\end{array}$ & $\begin{array}{l}3.76 \pm 2.97 \\
7.24 \pm 2.81\end{array}$ & $\begin{array}{l}t=-10.111 \\
p=0.000^{*}\end{array}$ & $\begin{array}{l}29.52 \pm 7.79 \\
22.44 \pm 7.65\end{array}$ & $\begin{array}{c}t=7.770 \\
p=0.000^{*}\end{array}$ \\
\hline $\begin{array}{l}\text { Educational Level }{ }^{\mathrm{x}} \\
\text { Literate }^{\mathrm{a}} \\
\text { Primary/Secondary }{ }^{\mathrm{b}} \\
\text { High School c } \\
\text { University }{ }^{\mathrm{d}} \\
\end{array}$ & $\begin{array}{c}66 \\
206 \\
28 \\
11 \\
\end{array}$ & $\begin{array}{c}21.3 \\
66.2 \\
9.0 \\
3.5 \\
\end{array}$ & $\begin{array}{l}7.55 \pm 2.84 \\
4.60 \pm 3.23 \\
3.18 \pm 2.23 \\
1.91 \pm 2.07 \\
\end{array}$ & $\begin{array}{l}x^{2}=58.510 \\
p=0.000^{*}\end{array}$ & $\begin{array}{l}22.68 \pm 8.03 \\
27.31 \pm 8.04 \\
31.54 \pm 7.47 \\
35.36 \pm 7.38 \\
\end{array}$ & $\begin{array}{l}x^{2}=37.024 \\
p=0.000 *\end{array}$ \\
\hline $\begin{array}{l}\text { Labor Status } \\
\text { Working } \\
\text { Not working } \\
\text { Retired }\end{array}$ & $\begin{array}{c}38 \\
63 \\
210\end{array}$ & $\begin{array}{l}20.3 \\
12.2 \\
67.5\end{array}$ & $\begin{array}{l}4.50 \pm 3.39 \\
6.81 \pm 2.85 \\
4.55 \pm 3.32\end{array}$ & $\begin{array}{l}F=12.317 \\
p=0.000 *\end{array}$ & $\begin{array}{l}27.50 \pm 9.92 \\
24.27 \pm 7.81 \\
27.72 \pm 8.20\end{array}$ & $\begin{array}{c}F=4.211 \\
p=0.016 \text { ** }\end{array}$ \\
\hline $\begin{array}{l}\text { Income Level } \\
\text { High } \\
\text { Moderate } \\
\text { Low }\end{array}$ & $\begin{array}{c}84 \\
212 \\
15\end{array}$ & $\begin{array}{c}27.0 \\
68.2 \\
4.8 \\
\end{array}$ & $\begin{array}{l}3.79 \pm 3.23 \\
5.34 \pm 3.30 \\
6.93 \pm 2.92 \\
\end{array}$ & $\begin{array}{l}x^{2}=20.574 \\
p=0.000 *\end{array}$ & $\begin{array}{l}30.99 \pm 8.24 \\
25.49 \pm 8.14 \\
25.87 \pm 6.61 \\
\end{array}$ & $\begin{array}{l}x^{2}=25.883 \\
p=0.000 *\end{array}$ \\
\hline $\begin{array}{l}\text { Status of Smoking } \\
\text { Smoker } \\
\text { No history of smoking } \\
\text { Ex-smoker }\end{array}$ & $\begin{array}{c}83 \\
57 \\
171\end{array}$ & $\begin{array}{l}26.7 \\
18.3 \\
55.0\end{array}$ & $\begin{array}{l}5.29 \pm 3.55 \\
4.49 \pm 3.17 \\
5.03 \pm 3.32\end{array}$ & $\begin{array}{l}F=0.969 \\
p=0.381\end{array}$ & $\begin{array}{l}27.58 \pm 9.04 \\
26.75 \pm 8.31 \\
26.79 \pm 8.22\end{array}$ & $\begin{array}{l}F=0.271 \\
p=0.763\end{array}$ \\
\hline $\begin{array}{l}\text { Alcohol Consumption } \\
\text { Not drinking } \\
\text { Drinking/Stopped drinking }\end{array}$ & $\begin{array}{c}226 \\
85\end{array}$ & $\begin{array}{l}72.7 \\
27.3\end{array}$ & $\begin{array}{l}5.33 \pm 3.45 \\
4.12 \pm 2.94\end{array}$ & $\begin{array}{c}t=3.090 \\
p=0.002^{\star \star}\end{array}$ & $\begin{array}{l}26.49 \pm 8.31 \\
28.83 \pm 8.68\end{array}$ & $\begin{array}{l}t=-1.717 \\
p=0.087\end{array}$ \\
\hline \multicolumn{7}{|c|}{ Hospitalization due to exacerbation of COPD during the last 12 months } \\
\hline $\begin{array}{l}\text { Yes } \\
\text { No }\end{array}$ & $\begin{array}{l}123 \\
188\end{array}$ & $\begin{array}{l}39.9 \\
60.1\end{array}$ & $\begin{array}{l}6.79 \pm 3.14 \\
3.83 \pm 2.96\end{array}$ & $\begin{array}{c}t=-8.312 \\
p=0.000^{*}\end{array}$ & $\begin{array}{l}24.31 \pm 8.06 \\
28.75 \pm 8.24\end{array}$ & $\begin{array}{c}t=-4.710 \\
p=0.000^{*}\end{array}$ \\
\hline \multicolumn{7}{|l|}{ The use of oxygen at home } \\
\hline $\begin{array}{l}\text { Yes } \\
\text { No }\end{array}$ & $\begin{array}{c}78 \\
233\end{array}$ & $\begin{array}{l}25.1 \\
74.9\end{array}$ & $\begin{array}{l}7.64 \pm 2.72 \\
4.12 \pm 3.08\end{array}$ & $\begin{array}{c}t=-9.004 \\
p=0.000^{*}\end{array}$ & $\begin{array}{l}21.44 \pm 6.66 \\
28.85 \pm 8.16\end{array}$ & $\begin{array}{l}t=-7.258 \\
p=0.000^{*}\end{array}$ \\
\hline \multicolumn{7}{|l|}{ Comorbidities out of COPD } \\
\hline $\begin{array}{l}\text { Yes } \\
\text { No }\end{array}$ & $\begin{array}{l}148 \\
163\end{array}$ & $\begin{array}{l}47.6 \\
52.4\end{array}$ & $\begin{array}{l}5.87 \pm 3.28 \\
4.21 \pm 3.24\end{array}$ & $\begin{array}{l}t=-4.494 \\
p=0.000 *\end{array}$ & $\begin{array}{l}25.75 \pm 7.73 \\
28.12 \pm 8.91\end{array}$ & $\begin{array}{c}t=-2.497 \\
p=0.013^{\star \star}\end{array}$ \\
\hline \multicolumn{7}{|l|}{ Polypharmacy ( $\geq 5$ drugs) } \\
\hline $\begin{array}{l}\text { Yes } \\
\text { No }\end{array}$ & $\begin{array}{c}32 \\
279\end{array}$ & $\begin{array}{l}11.5 \\
88.5\end{array}$ & $\begin{array}{l}7.38 \pm 3.18 \\
4.73 \pm 3.27\end{array}$ & $\begin{array}{l}t=-4.447 \\
p=0.000^{*}\end{array}$ & $\begin{array}{l}23.25 \pm 6.76 \\
27.42 \pm 8.52\end{array}$ & $\begin{array}{c}t=-2.675 \\
p=0.008^{* *}\end{array}$ \\
\hline
\end{tabular}

${ }^{\star} p<0,001 ;{ }^{* \star} p<0,05$ t: Independent Sample t test Z: Kruskall Wallis H F: One Way ANOVA

$\times$ Tukey's HSD Test y Bonferroni (Dunn) Test

$a>b>c=d$. Underlined groups that cause significant differences between groups. 
tive correlation was found between $\mathrm{FEV}_{1}$ values and frailty level $(r=-0.344 ; p<0.001)$. A low level of negative correlation was found between the patients' level of acceptance of illness and their ages ( $r=$ $-0.447)$, mMRC scores $(r=-0.461)$, years of COPD ( $r$ $=-0.383)$ and NRS-2002 scores $(r=-0.466)(p<0.001)$. Also a low level of positive correlation was found between $\mathrm{FEV}_{1}$ values and level of acceptance of illness ( $r=0.467 ; p<0.001)$. A high level of negative correlation was found between the patients' frailty level and their level of acceptance of illness $(p<0.05$, $r=-0.747$ ) (Table 3).

The explanatory power of the models developed by multivariate linear regression analysis (Adjust $\mathrm{R}^{2}$ ) varies between $55.6 \%$ and $61.6 \%$. According to multiple linear regression analysis, the explanatory power of the relationship between fragility level and acceptance of illness was found to be $55.6 \%$ (Model $1 ; \boldsymbol{\beta}=-0.747$, Adjust $\left.\mathrm{R}^{2}=0.556, \mathrm{p}<0.001\right)$. The explanatory power of frailty level and $\mathrm{FEV}_{1}$ values together on acceptance of illness was $60.5 \%$ (Model 2; Adjust $\left.R^{2}=0.605, p<0.001\right)$. The explanatory

Table 3. Correlation coefficients between some variables of the patients and their frailty and Acceptance of Illness Scale (AIS) Scores $(n=311)$

\begin{tabular}{|c|c|c|}
\hline Characteristics & $\begin{array}{c}\text { Edmonton Frailty } \\
\text { Scale }\end{array}$ & $\begin{array}{l}\text { Acceptance of } \\
\text { Illness Scale }\end{array}$ \\
\hline Age & $\begin{array}{c}r=0.573 \\
p=0.000 *\end{array}$ & $\begin{array}{c}r=-0.447 \\
p=0.000 *\end{array}$ \\
\hline Year of COPD & $\begin{array}{c}r=0.344 \\
p=0.000 *\end{array}$ & $\begin{array}{c}r=-0.383 \\
p=0.000 *\end{array}$ \\
\hline $\mathrm{FEV}_{1}$ & $\begin{array}{c}r=-0.344 \\
p=0.000 *\end{array}$ & $\begin{array}{c}r=0.467 \\
p=0.000^{*}\end{array}$ \\
\hline $\mathrm{mMRC}$ & $\begin{array}{c}r=0.569 \\
p=0.000 \text { * }\end{array}$ & $\begin{array}{c}r=-0.461 \\
p=0.000 *\end{array}$ \\
\hline NRS-2002 & $\begin{aligned} r & =0.536 \\
p & =0.000 *\end{aligned}$ & $\begin{array}{c}r=-0.466 \\
p=0.000 *\end{array}$ \\
\hline $\begin{array}{l}\text { Edmonton Frailty } \\
\text { Scale }\end{array}$ & 1 & $\begin{array}{c}r=-0.747 \\
p=0.000 *\end{array}$ \\
\hline
\end{tabular}

power of frailty level, $\mathrm{FEV}_{1}$, and NRS-2002 values on acceptance of illness was 61.2\% (Model 3; Adjust R2 $=0.612, p<0.001)$. And frailty level, FEV 1 , NRS-2002, and $\mathrm{mMRC}$ values were found to be $61.6 \%$ (Model 4; Adjust $\mathrm{R}^{2}=0.616, \mathrm{p}<0.001$ ) (Table 4).

\section{DISCUSSION}

To the best of our knowledge, this study is the first study to investigate the relationship and effect between frailty level and acceptance of illness level in older people with COPD. Older people with COPD included in this study had a very low score of frailty of 5.00 (SD 3.36). Almost half of the patients (49.8\%) were not frail. However, based on similar studies, this rate is reported to be higher in other countries $(16,17)$. Contrary to the level of frailty, the score of acceptance of illness in COPD patients included in our study was 26.99 (SD 8.44), which is above average. Although there are no studies investigating the level of acceptance of illness of patients with COPD in our country, our results were similar to the results found in other countries $(18,19)$.

In this study, the women's frailty scores were higher than the men's. In the first large-scale frailty study conducted by Fried et al. (2001), women were reported to be frailer (20). Married older people had lower frailty and higher acceptance of illness scores than single or widowed patients. The presence of a spouse has a positive effect on the psychosocial sub-dimension of frailty syndrome; likewise, higher levels of acceptance of illness can be described in terms of social and psychological support of the spouse. A significant difference was also found between levels of frailty and acceptance of illness and level of education as another socio-demographic variable. According to our results, as the education level increased, the frailty scores decreased and the levels of acceptance of illness increased. In this context, the studies were also consistent with our results $(18,21)$. In the present study, it was concluded that the unemployed patients had a higher frailty level and lower acceptance of illness level than those 
Table 4. The relationship between some variables and acceptance of the disease level of frailty according to multiple linear regression analysis $(n=311)$

\begin{tabular}{|c|c|c|c|c|c|c|}
\hline Models & $\mathrm{B}(95.0 \% \mathrm{Cl}$ for $\mathrm{B})$ & $\beta$ & $t$ & $p$ & Adjust $\mathrm{R}^{2}$ & Model $p$ \\
\hline \multicolumn{7}{|l|}{ Model 1. AIS } \\
\hline EFS & $-1.877(-2.064,-1.689)$ & -0.747 & -19.723 & 0.000 & 0.556 & 0.000 \\
\hline \multicolumn{7}{|l|}{ Model 2. AIS } \\
\hline EFS & $-1.671 \quad(-1.859,-1.483)$ & -0.665 & -17.478 & 0.000 & 0.605 & 0.000 \\
\hline $\mathrm{FEV}_{1}$ & $0.115 \quad(0.079,0.151)$ & 0.238 & 6.259 & 0.000 & & \\
\hline \multicolumn{7}{|l|}{ Model 3. AIS } \\
\hline EFS & $-1.518(-1.737,-1.299$ & -0.604 & -13.633 & 0.000 & & \\
\hline $\mathrm{FEV}_{1}$ & $0.118 \quad(0.082,0.154)$ & 0.244 & 6.468 & 0.000 & 0.612 & 0.000 \\
\hline NRS-2002 & $-1.119(-1.959,-0.278)$ & -0.110 & -2.618 & 0.009 & & \\
\hline \multicolumn{7}{|l|}{ Model 4. AIS } \\
\hline EFS & $-1.627 \quad(-1.867,-1.386$ & -0.647 & -13.321 & 0.000 & & \\
\hline $\mathrm{FEV}_{1}$ & $0.139 \quad(0.098,0.180)$ & 0.288 & 6.714 & 0.000 & 0.616 & 0.000 \\
\hline NRS-2002 & $-1.125 \quad(-1.961,-0.289)$ & -0.110 & -2.648 & 0.009 & & \\
\hline $\mathrm{mMRC}$ & $0.869 \quad(0.60,1.677)$ & 0.103 & 2.113 & 0.035 & & \\
\hline
\end{tabular}

AIS: Acceptance of Illness Scale EFS: Edmonton Frailty Scale; B: unstandardized coefficients; Cl: confidence interval; $\boldsymbol{\beta}$ : standardized regression coefficient; $R^{2}$ : coefficient of determination.

who had retired or still continued to work. Similarly, in their study on diabetic patients in Turkey, Şireci and Yılmaz Karabulutlu (2017) reported that unemployed patients had a lower level of acceptance of illness (11). This situation can be explained by the fact that almost all of the unemployed people in our country are women, and they are "housewives" who live a sedentary life. In terms of income status, it was found that older COPD patients with a good income had lower levels of frailty and higher acceptance of illness scores than patients with moderate or low income. This can be explained by the fact that better socioeconomic conditions can provide easier access to adequate food, health services and medicines.

Older COPD patients who were using alcohol or those who had quit using it had lower frailty scores. This difference can be explained based on the fact that all of these patients in our study were male. Smoking, however, did not have any effect on the frailty and acceptance of illness scores.

Patients who were hospitalized due to COPD exacerbation in the past year had higher frailty and lower acceptance of illness scores. This result can be explained by the fact that the dyspnoea and inactivity experienced by patients during COPD exacerbation contribute to the deterioration of their physical activity (reduction in walking speed, loss of muscle strength), which are common features of frailty syndrome. The mean acceptance of illness score of the hospitalized COPD patients reported by Uchmanowicz et al. (2016) was lower than the results in our study (13). Similarly, in our study, it was concluded that older people who used oxygen devices in their homes had higher frailty and lower acceptance of the disease than those who did not use these devices. This can be explained by the failure of the patients to comply with oxygen therapy on one hand, and deterioration of quality of life as a negative impact of the disease on the other; both 
of these adversely affect the level of acceptance of illness.

Patients with comorbidities besides COPD, and with polypharmacy, had higher frailty and lower acceptance of illness scores. Although comorbidity is different from frailty and disability, they may aggravate each other and contribute to the progression of frailty (22). An increase in the amount of drugs used, which is in direct relationship with the number of comorbidities, may be a risk factor for frailty.

Age was positively related to frailty, and as it increased the level of frailty increased moderately. This result was consistent with studies conducted in other countries $(20,23,24)$. Physiological and cognitive changes caused by aging which lead to frailty can explain this situation. In contrast to this, age was negatively correlated with the acceptance level of the disease. While Nowicki, Krzemkowska and Rhone (2015) found no correlation between age and acceptance of illness in their study on cancer patients, the results of Mroczek et al. (2015) and Jankowska-Polaǹska et al. (2015) in their study on the level of acceptance of illness in COPD patients were consistent with our study $(18,19,23)$. The duration of COPD, FEV 1 values, and mMRC scores, which are all parameters of COPD, were correlated with the levels of frailty and acceptance of illness. Considering the fact that longer duration of COPD, lower FEV 1 values, and higher mMRC scores are all indicators of higher levels of severity and the burden of COPD, they all lead to an increased level of frailty and decreased level of acceptance of illness. Similar to our study, in their study on Polish patients, Jankowska-Polaǹska et al. (2016) reported that as the burden of COPD increases, older patients have difficulty in accepting their disease (21). Furthermore, Maddocks et al. (2016) found that COPD patients with low $\mathrm{FEV}_{1}$ values and high mMRC scores were frailer due to reduced lung capacity and difficulties caused by dyspnoea (16). NRS-2002 scores had a positive correlation with the level of frailty and a negative correlation with the level of acceptance of illness. Similar to our results, Machón et al. (2018) also reported that frail people were more prone to malnutrition risk. The fact that chronic malnutrition causes sarcopenia and indirectly leads to frailty can explain this situation (25).

In this study, there was a strong negative correlation between frailty level and acceptance of illness in patients older than 65 years. In this context, the increase in the vulnerability of older people may be due to a decrease in the level of acceptance as a strong factor. In contrast to our study, in their study on hospitalized COPD patients with a mean age of 63.2, Uchmanowicz et al. (2016) used a different measurement tool to evaluate frailty, and reported a weak negative correlation between the physical and social subscales of frailty and acceptance of illness level, yet they found no correlation between total frailty score and acceptance of illness level (13). It can be assumed that independent variables such as age and hospitalization can change the direction and strength of the relationship between the level of frailty and the level of acceptance of illness.

When the literature is examined, although there are studies examining the relationship between the level of frailty and acceptance of the disease, no study has been found that indicates the explanatory power of this relationship. In this respect, the explanatory power of other independent variables related to acceptance of the disease, as well as the level of frailty with a high level of negative correlation and acceptance of the disease, were examined. As a result, the combination of frailty level, $\mathrm{FEV}_{1}$ value, NRS-2002 score and mMRC value according to statistically established models explained the acceptance of illness level at a rate of $61.6 \%$; The level of frailty alone explains the acceptance of the disease at a rate of $55.6 \%$. As a result, it is thought that attempts to increase the acceptance of the disease in older people with COPD will make a great contribution to reducing frailty, which is a biopsychosocial syndrome. 


\section{Limitations}

First, the study has a descriptive and correlated design; therefore, the results of the study cannot suggest causality. We evaluated only older people admitted to the outpatient clinics. Finally, the sample was small and the findings were limited to a single department of a single hospital in Turkey. These disadvantages, together with our non-random sam-

\section{REFERENCES}

1. Mathers CD, Loncar D. Projections of Global Mortality and Burden of Disease from 2002 to 2030. Samet J, ed. PLoS Med. 2006;3(11):2011-2030. (PMID: 17132052)

2. World Healt Organization. Global Surveillance, Prevention and Control of Chronic Respiratory Diseases a Comprehensive Approach [e-book] WHO Publication; 2007. [Internet]. Available from: http://www. who.int/respiratory/copd/burden/en/ Accessed: 11.01.2021

3. Turkish Public Health Institution. Prevalence of Chronic Diseases and Risk Factors in Turkey [e-book] Ministry of Health Publication; 2013. [Internet]. Available from: https://sbu.saglik.gov.tr/Ekutuphane/ kitaplar/khrfat.pdf Accessed: 11.01.2021

4. Global Initiative for Chronic Obstructive Lung Disease 2020 Report [e-book]. Available from: https:// goldcopd.org/wp-content/uploads/2019/12/GOLD2020-FINAL-ver1.2-03Dec19_WMV.pdf Accessed: 11.01.2021

5. Eyigör S. Geriatric Syndromes. Turk J Phys Med Rehab. 2009; 55 (Suppl 2): 57-61. (DOI:10.19161/ etd.27665) (in Turkish)

6. Eyigör S, Gökçe Kutsal Y. Approach to the Frail Elderly. Turk J Phys Med Rehab. 2010; 56(3): 135-140. (DOI:10.4274/tftr.56.135) (in Turkish)

7. Kapucu S, Ünver G. Fragile Elderly and Nursing Care. Osmangazi Journal of Medicine. 2017;39(1):122-129. (DOI:10.20515/otd.288967) (in Turkish)

8. Besen DB, Esen A. The Adaptation of the Acceptance of Illness Scale to the Diabetic Patients in Turkish Society. TAF Prev Med Bull. 2011; 10(2): 155-164. (DOI:10.5455/pmb.20110304120542) (in Turkish)

9. Czerw Al, Bilińska M, Deptała A. The Assessment of the Impact of Socio-Economic Factors in Accepting pling and data collection in only one centre, limit the generalizability of findings to all Turkish older people with COPD. Even with these limitations, this study provides a better understanding of the relationship between frailty and acceptance of illness in older people with COPD. This study provides instructions for future longitudinal or experimental studies.

Cancer Using the Acceptance of Illness Scale (AIS). Contemp Oncol (Pozn). 2016;20(3):261-265. (PMID: 27647992)

10. Kostyła M, Tabaał K, Kocur J. Illness Acceptance Degree versus Intensity of Psychopathological Symptoms in Patients with Psoriasis. Postepy Dermatol Alergol. 2013;30(3):134-139. (PMID: 24278064)

11. Şireci E, Yılmaz Karabulutlu E. Diabetes Mellitus Type II Patients' Acceptance of Illness and Determination of Self Efficacy Levels for Their Care. Journal of Anatolia Nursing and Health Sciences. 2017;20(1):48-55. (DOI:10.17049/ahsbd.07988) (in Turkish)

12. Mlynarska A, Mlynarski R, Golba KS. Older Age and a Higher EHRA Score Allow Higher Levels of Frailty Syndrome to Be Predicted in Patients with Atrial Fibrillation. Aging Male. 2017;20(1):23-27. (PMID: 27841074)

13. Uchmanowicz I, Jankowska-Polanska B, Chabowski $\mathrm{M}$ et al. The Influence of Frailty Syndrome on Acceptance of Illness in Elderly Patients with Chronic Obstructive Pulmonary Disease. Int J Chron Obstruct Pulmon Dis. 2016;11(1):2401-2407. (PMID: 27729781)

14. Bolayir B, Arik G, Yeşil $Y$ et al. Validation of Nutritional Risk Screening-2002 in a Hospitalized Adult Population. Nutr Clin Pract. 2019;34(2):297-303. (PMID: 29603374)

15. Aygör HE, Fadıloğlu Ç, Şahin S et al. Validation of Edmonton Frail Scale Into Elderly Turkish Population. Arch Gerontol Geriatr. 2018;76(January 2017):133137. (PMID: 29499529)

16. Maddocks M, Kon SSC, Canavan JL et al. Physical Frailty and Pulmonary Rehabilitation in COPD: A Prospective Cohort Study. Thorax. 2016;71(11):988995. (PMID: 27293209)

17. Uchmanowicz I, Jankowska-Polanska B, Motowidlo $U$ et al. Assessment of Illness Acceptance by Patients with COPD and the Prevalence of Depression and 
Anxiety in COPD. Int J Chron Obstruct Pulmon Dis. 2016;11(1):963-970. (PMID: 27274217)

18. Jankowska-Polańska B, Kasprzyk M, Chudiak A et al. Relation between IIIness Acceptance and Quality of Life in Patients with Chronic Obstructive Pulmonary Disease (COPD). Pneumonol Alergol Pol. 2016;85(1):3-10. (PMID: 26687669)

19. Mroczek B, Sitko Z, Augustyniuk K et al. Socioeconomic Indicators Shaping Quality of Life and Illness Acceptance in Patients with Chronic Obstructive Pulmonary Disease. Adv Exp Med Biol. 2015;861:19-30. (PMID: 26017727)

20. Fried LP, Tangen CM, Walston J et al. Frailty in Older Adults: Evidence for a Phenotype. J Gerontol A Biol Sci Med Sci. 2001;56(3):M146-M157. (PMID: 11253156)

21. Jankowska-Polaǹka B, Blicharska K, Uchmanowicz I et al. The Influence of Illness Acceptance on the Adherence to Pharmacological and Non-Pharmacolog- ical Therapy in Patients with Hypertension. Eur J Cardiovasc Nurs. 2016;15(7):559-568. (PMID: 26743263)

22. Çakmur H. Frailty among Elderly Adults in a Rural Area of Turkey. Med Sci Monit. 2015;21:1232-1242. (PMID: 25925800)

23. Nowicki A, Krzemkowska E, Rhone P. Acceptance of Illness after Surgery in Patients with Breast Cancer in the Early Postoperative Period. Pol Przegl Chir. 2015;87(11):539-550. (PMID: 26816401)

24. Fried LP, Ferrucci L, Darer J et al. Untangling the Concepts of Disability, Frailty, and Comorbidity: Implications for Improved Targeting and Care. J Gerontol A Biol Sci Med Sci. 2004;59(3):M255-M263. (PMID: 15031310)

25. Machón M, Mateo-Abad M, Vrotsou K et al. Dietary Patterns and Their Relationship with Frailty in Functionally Independent Older Adults. Nutrients. 2018;10(4):1-12. (PMID: 29587356) 